Sandrine Vuillaumier-Barrot • Christiane Le Bizec

Geneviève Durand $\cdot$ Nathalie Seta

\title{
The T911C (F304S) substitution in the human ALG6 gene is a common polymorphism and not a causal mutation of CDG-Ic
}

Received: March 6, 2001 / Accepted: June 1, 2001

\begin{abstract}
A T911C (F304S) substitution in the ALG6 gene involved in congenital disorder of glycosylation type Ic (OMIM 603147) has been described. However, whether the F304S substitution is a common polymorphism or a causal mutation remains unclear. We screened for the T911C substitution in the $A L G 6$ gene in 54 unrelated healthy French individuals. We developed a restriction fragment length polymorphism assay with a mutagenic primer introducing a diagnostic $D d e$ I restriction site. We found 23 heterozygotes $(42.6 \%)$ and 3 homozygous individuals $(5.5 \%)$. This result indicates that $\mathrm{T} 911 \mathrm{C}$ is a common polymorphism with an allele frequency of $27 \%$ in a French population and not a causal mutation of congenital disorder of glycosylation type Ic.
\end{abstract}

Key words ALG6 · $\alpha 1,3$-Glucosyltransferase $\cdot$ Congenital Disorder of Glycosylation-Ic · Polymorphism - CDG . F304S

\section{Introduction}

Congenital disorder of glycosylation (CDG) type Ic (OMIM 603147) is an autosomal recessive disorder characterized by central nervous system dysfunction associated with defective serum glycoprotein $\mathrm{N}$-glycosylation, a dolichyl pyrophosphate Man9GlcNAc2 alpha1,3glucosyltransferase deficiency, and mutations in the $A L G 6$ gene (Imbach et al. 1999). Three recent studies described a T911C (F304S) substitution in the ALG6 gene (Imbach et al. 2000; Westphal et al. 2000; Hanefeld et al. 2000). However, in these studies, whether T911C substitution was a common polymorphism or a causal mutation remained unclear. In order to determine the role of F304S, T911C was screened for in a healthy French population.

S. Vuillaumier-Barrot $\cdot$ C. Le Bizec $\cdot$ G. Durand $\cdot$ N. Seta $(\square)$

Biochimie A, Hôpital Bichat-Claude Bernard, 46 rue Henri

Huchard, 75877-Paris cedex 18, France

Tel. +33 1402585 43; Fax +33140258821

e-mail: nathalie.seta@bch.ap-hop-paris.fr

\section{Materials and methods}

We developed a restriction fragment length polymorphism (RFLP) assay with a mutagenic primer introducing a diagnostic restriction site. We used the following primers: F304S, 5'-GCA GGA AGC AGG CTC AAA AAC TTA3'; and ALG6 10 FD, 5'-AAA CTT AAG TTG ATA AAT AAT ATG ATC CTT- $3^{\prime}$. Polymerase chain reaction (PCR) analysis was performed in a $25-\mu \mathrm{l}$ volume containing $500 \mathrm{ng}$ genomic DNA, $0.2 \mathrm{mM}$ each dNTP, $5 \mathrm{pmol}$ each primer, 1.5 unit Taq polymerase GOLD (Perkin Elmer, Norwalk, CT USA), $2 \mathrm{mM} \mathrm{MgCl} 2$, and buffer from the manufacturer. Using a UNO II thermocycler (Biometra, Kent, UK), initial denaturation at $95^{\circ} \mathrm{C}$ for $7 \mathrm{~min}$ was followed by 35 cycles at $95^{\circ} \mathrm{C}$ for $30 \mathrm{~s}$, annealing at $52^{\circ} \mathrm{C}$ for $30 \mathrm{~s}$ and extension at $72^{\circ} \mathrm{C}$ for $40 \mathrm{~s}$, with a final extension step of $5 \mathrm{~min}$ at $72^{\circ} \mathrm{C}$. The PCR products were digested by DdeI and then electrophoresed on a $10 \%$ bis acrylamide gel, which separated a 148-bp fragment, in the absence of the polymorphism, from a 122-pb digested fragment, in the presence of the polymorphism, the F304S mutagenic primer having created a DdeI restriction site.

We screened 54 unrelated healthy French subjects from the laboratory staff, who all gave their informed consent.

\section{Results}

The distribution of genotypes and allele frequencies is shown in Table 1 . We found among 54 unrelated individuals 23 heterozygotes $(42.6 \%)$ and 3 homozygous individuals $(5.5 \%)$. The distribution did not differ significantly from the expected one assuming Hardy-Weinberg equilibrium.

\section{Discussion}

The list of mutations in CDG I-c is available on line (URL: http://www.kuleuven.ac.be/med/cdg); seven different mutations, F304S included, are described, representing 19 alleles. 
Table 1. Distribution of genotypes and allele frequencies of T911C (F304S) polymorphic alleles in the $A L G 6$ gene in unrelated healthy French subjects

\begin{tabular}{lcc}
\hline Genotypes & Observed no. & Expected no. \\
\hline$T T$ & 28 & 29 \\
$T C$ & 23 & 21 \\
$C C$ & 3 & 4 \\
Total & 54 & 54
\end{tabular}

Allele frequencies; $\mathrm{T}=73 \%, \mathrm{C}=27 \%$

$\chi^{2}=0.4749 ;$ degrees of freedom $(\mathrm{df})=1 ; P=0.5$

The F304S substitution is located close to two other mutations, A333V (Imbach et al. 1999) and delI299 (Hanefeld et al. 2000) suggesting that it may also have an effect on residual activity. Hanefeld et al. described a patient's cDNA diverging at two positions from the published sequence, delI299 and F304S, but the precise allelic place of the two substitutions was not given. In addition, the DNA level was not investigated, thus excluding the possibility of finding a splice mutation (Hanefeld et al. 2000). Furthermore, a complementation analysis was performed in the Saccharomyces cerivisiae $\triangle \mathrm{ALG} 6$ mutant strain showing that cDNAs with the A333V and S478P substitutions failed to correct the glycosylation defect. In contrast, the F304S cDNA corrected it, restoring function to levels similar to those achieved by the normal cDNA (Imbach et al. 2000). Howewer, the analysis of the yeast growth demonstrated a negative effect of the F304S mutation on ALG6 integrity, suggesting that F304S could be a milder mutation (Imbach et al. 2000). Until now, whether or not F304S was a causal mutation remained unclear. We found homozygous T911C (F304S) substitution in the $A L G 6$ gene in healthy subjects. Taken together, our results clearly suggest that F304S is probably a benign common polymorphism. This finding will contribute to our understanding of this new genetic disease.

\section{References}

Hanefeld F, Körner C, Holzbach-Eberle U, von Figura K (2000) Congenital Disorder of Glycosylation-Ic: case report and genetic defect. Neuropediatrics 31:60-62

Imbach T, Burda P, Kuhnert P, Wevers RA, Aebi M, Berger EG, Hennet T (1999) A mutation in the human ortholog of the Saccharomyces cerevisiae ALG6 gene causes carbohydrate-deficient glycoprotein syndrome type-Ic. Proc Natl Acad Sci USA 96:6982-6987

Imbach T, Grunewald S, Schenk B, Burda P, Schollen E, Wevers RA, Jaeken J, de Klerk JB, Berger EG, Matthijs G, Aebi M, Hennet T (2000) Multi-allelic origin of Congenital Disorder of Glycosylation (CDG)-Ic. Hum Genet 106:538-545

Westphal V, Schottstadt C, Marquardt T, Freeze HH (2000) Analysis of multiple mutations in the hALG6 gene in a patient with congenital disorder of glycosylation Ic. Mol Genet Metab 70:219-223 